\section{Re-uniting philosophy and neuroscience}

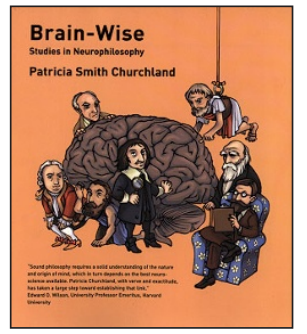

\author{
Brain-Wise: Studies in \\ Neurophilosophy
}

By Patricia Smith Churchland

MIT Press, $2002 \$ 25.00$

paperback, pp 438

ISBN 026253200

\section{Reviewed by Sarah-Jayne Blakemore}

Although 'neurophilosophy' sounds like a new cross-disciplinary degree program, it is actually an ancient concept. The Greek philosophers Alcmaeon and Hippocrates were the founders of empirical neuroscience, writing extensively about philosophical conundrums as well as the brain's role in the solution to these problems. Alcmaeon (c. $500 \mathrm{BC}$ ) regarded the brain as the central organ of sensation, a conclusion he reached after excising the eyeball of an animal and discovering that the visual tracts were connected to the brain. Building on this notion, Hippocrates (c. $460 \mathrm{BC}$ ) stressed the brain's role in emotional and cognitive processes: "Not only our pleasure, our joy and our laughter but also our sorrow, pain, grief and tears arise from the brain, and the brain alone; with it we think and understand, see and hear and we discriminate between the ugly and the beautiful, between what is pleasant and what is unpleasant and between good and evil".

For millennia there was no hard distinction between science and philosophy. Great thinkers, including Copernicus, Galileo and Descartes, who contemplated the meaning of the universe and life itself often tinkered with empirical research. Over the centuries, however, philosophy and science have become much more academically isolated: science courses usually contain little if any philosophy, and modern philosophers typically eschew empiricism. Only relatively recently have the two domains rediscovered and begun to borrow from each other. Scientists might couch their experiments in philosophical inquiry; recent examples that come to mind are Daniel Wegner's empirical endeavor to characterize the perception of free will and Joshua Greene and Jonathan Cohen's research on the neural correlates of moral dilemmas. Many philosophers concede that the study of the brain can contribute to philosophical thinking.

Patricia Smith Churchland's 1986 book Neurophilosophy was a landmark for re-uniting philosophy and neuroscience. Now in her new book, Brain-Wise, she begins with a historical overview and subsequently describes the evolution of philosophical thinking and its relation to brain science. Addressing topics as diverse as the self, consciousness and religion from the perspective of brain science, she

Sarah-Jayne Blakemore is a Wellcome Trust Research Fellow at the Institute of Cognitive Neuroscience, 17 Queen Square, London WC1N 3AR, UK.

e-mail: s.blakemore@ucl.ac.uk embeds each discussion in the context of an ancient philosophical problem. Who am "I"? Does God exist? Churchland, who chairs the philosophy department at the University of California, San Diego, claims that finding answers to these questions requires empirical research, particularly brain research: "It is the brain, rather than some nonphysical stuff, that feels, thinks and decides," she says.

Although it is widely accepted that science must be considered when contemplating such questions, there is still a substantial gap between philosophical questions on the one hand and basic neuroscience findings on the other. The prefrontal cortex might be involved in willed actions, but knowing that does not tell us how actions are willed, the link between intention and action or why we feel in control of our actions. The reliance on processes in the brain to explain all that is human might lead some to worry about reductionism. However, each chapter of Brain-Wise contains extensive descriptions of cognitive psychology experiments and cognitive models, both of which are offered as solutions to philosophical questions and thus bridge the chasm between philosophy and basic brain research.

Let's take the problem of the 'self', which is set in the context of David Hume's paradox that although "I think I am something," the self is not observable in the way that the body is. Churchland argues that, "in this century we have the advantage of addressing Hume's question within the framework of neuroscience". In addition to discussing autobiographical memories and various disorders of self-representation, Churchland focuses on the problem of agency: how do I know this action is my own? This issue has recently been approached empirically in the field of motor control, where 'forward models' are used to explain how we recognize our own actions. One function of forward models, which were originally designed to solve engineering problems and are now the focus of cognitive research, is to distinguish selfproduced and externally produced events. Briefly, a forward model of a self-generated movement results in a prediction of the sensory consequences of that movement, and this prediction is used to cancel the sensory results of one's actions. Thus self-produced sensations are attenuated relative to external sensations because the latter cannot be predicted. It is this feature of internal models that Churchland suggests can make a useful contribution within philosophy.

This type of trans-disciplinarity is evident throughout Brain-Wise. Churchland is knowledgeable in several different disciplines and does an impressive job of linking disparate concepts. The benefits of her integrative work might not just be unidirectional (neuroscience informing philosophy). The question is, how can philosophy facilitate neuroscience? One way is through providing a conceptual background, insightful questions and definitions. In the burgeoning field of the self, for example, there is little consensus as to the definition of 'the self' among the many scientists who study it. One of the strengths of this book is its cautious definitions. Another is Churchland's clear and fluid writing style, which allows her to explain complicated concepts simply and to present complex arguments logically.

While being necessarily selective and subjective, Churchland tackles many of the big questions: consciousness, religion, morality, free will. One question that I couldn't find the answer to is "what will become of philosophy when all these questions are answered by science?" 